\title{
History Matters: Relating Land- Use Change to Butterfly Species Occurrence
}

\section{Journal Article}

Author(s):

Luetolf, Michael; Guisan, Antoine; Kienast, Felix

Publication date:

2009

Permanent link:

https://doi.org/10.3929/ethz-b-000115949

Rights / license:

In Copyright - Non-Commercial Use Permitted

Originally published in:

Environmental Management 43(3), https://doi.org/10.1007/s00267-008-9256-6 


\title{
History Matters: Relating Land-Use Change to Butterfly Species Occurrence
}

\author{
Michael Lütolf • Antoine Guisan · Felix Kienast
}

Received: 30 November 2007 / Accepted: 14 December 2008/Published online: 29 January 2009

(C) Springer Science+Business Media, LLC 2009

\begin{abstract}
Western European landscapes have drastically changed since the 1950s, with agricultural intensifications and the spread of urban settlements considered the most important drivers of this land-use/land-cover change. Losses of habitat for fauna and flora have been a direct consequence of this development. In the present study, we relate butterfly occurrence to land-use/land-cover changes over five decades between 1951 and 2000. The study area covers the entire Swiss territory. The 10 explanatory variables originate from agricultural statistics and censuses. Both state as well as rate was used as explanatory variables. Species distribution data were obtained from natural history collections. We selected eight butterfly species: four species occur on wetlands and four occur on dry grasslands. We used cluster analysis to track land-use/landcover changes and to group communes based on similar trajectories of change. Generalized linear models were applied to identify factors that were significantly correlated with the persistence or disappearance of butterfly species. Results showed that decreasing agricultural areas and densities of farms with more than 10 ha of cultivated land are significantly related with wetland species decline, and increasing densities of livestock seem to have favored disappearance of dry grassland species. Moreover, we
\end{abstract}

\footnotetext{
M. Lütolf · F. Kienast $(\square)$

Swiss Federal Research Institute WSL, Birmensdorferstrasse

111, 8903 Birmensdorf, Switzerland

e-mail: felix.kienast@wsl.ch

M. Lütolf

e-mail: michael.luetolf@ksbg.ch

M. Lütolf · A. Guisan

Laboratory for Conservation Biology (LBC), Department of Ecology and Evolution, University of Lausanne, BB, 1015

Lausanne, Switzerland
}

show that species declines are not only dependent on landuse/land-cover states but also on the rates of change; that is, the higher the transformation rate from small to large farms, the higher the loss of dry grassland species. We suggest that more attention should be paid to the rates of landscape change as feasible drivers of species change and derive some management suggestions.

Keywords Butterfly species - Cluster analysis . Generalized linear model · Historical data analysis . Natural history collection data $\cdot$ Rates of landscape change

\section{Introduction}

Landscapes in Western Europe have drastically changed since the 1950s and locally driven gradual processes have been largely replaced by more dynamic global forces. In Europe, and in particular in Switzerland, accelerated rates of land-use change were observed at least up to the 1990s (Schneeberger and others 2007). The post-1990 periods show lower rates of change due to a more sustainable use of land resources. Urbanization and technological advances in agriculture have been revealed as prominent causes of landscape change (Ewald 1978). Two opposing trends of land-use change have been identified: agricultural intensification on favorable land and land abandonment on marginal agricultural areas (Bätzing 2003; Ewald 1978). In this context, intensification has primarily occurred in flat areas with mostly deep and nutrient-rich soils. Consequently, landscape elements such as hedgerows, stone walls, or small ponds characteristic for traditional rural landscapes have been removed to facilitate treatment by farm machines. Land abandonment, on the other hand, has been observed in less productive areas or areas less easily 
accessible to machines. It has especially affected European mountain areas where agriculture is limited by the prevailing climatic conditions and the difficult topography.

Land-use/land-cover change has been widely recognized as an important driver of species change (e.g., Gaston and others 2003; Hutchinson and others 2000). Its impact on plant and animal species diversity has been shown in several empirical studies (Benton and others 2002; Chamberlain and others 2000; Cousins and Eriksson 2002; Dullinger and others 2003; Lundström-Gilliéron and Schlaepfer 2003). Both intensification and land abandonment might contribute to the decrease of species richness, even though land abandonment might temporary increase species richness due to newly initialized, natural succession processes (Laiolo and others 2004; Söderström and others 2001) that result in higher habitat heterogeneity.

Most studies showing a statistical relationship between historically documented land-use change and species abundance are rather limited in space. Often they are representative for a commune, county, or district only. An exception is the study of Lundström-Gilliéron and Schlaepfer (2003), who analyzed land-use/land-cover change on 936 communes in the northwestern part of Switzerland since the 1950s and its impacts on the abundance of brown hare (Lepus europaeus). They used communal statistical census data and showed that agricultural intensification as well as the spread of urban areas and the road and rail network are important drivers of the decline of the brown hare. By means of a cluster analysis of population censuses, Bätzing (2003) showed that processes of land abandonment and urbanization in the European Alps between 1871 and 2000 were correlated to areas of strong population decreases and increases, respectively. Cluster analysis also proved advantageous for investigating changes in a hedgerow network in France (Burel and Baudry 1990). The study analyzed the class membership of 26 contiguous research quadrates over four time periods and identified quadrates with different rates of change in the hedgerow network.

In the present study, we aim to explore historical landuse/land-cover changes in Switzerland for five time periods between the 1950s and 1990s to delineate areas with different historical land-use/land-cover developments and rates of change. Furthermore, we investigate the relationships between these land-use/land-cover changes and the persistence or disappearance of butterfly species occurring in either dry grassland or wetland habitats. This article presents four novel aspects: (1) the use of large-scale communal data and long-term species observations from natural history collections (Graham and others 2004); (2) the use of land-use data with a thematic precision that goes beyond land-cover data [e.g., NLCD (USA); CORINE (EU), or the Swiss area statistics]; (3) a bootstrap algorithm to select the important model parameters; and (4) the inclusion of land-use states and rates of change as explanatory variables in the models. With the latter, we challenge results from metapopulation models that have revealed probable impacts of the rate of environmental change on metapopulation survival (Bergman and Kindvall 2004; Brachet and others 1999; Schrott and others 2005). Because our primary objective is in detecting-but not forecasting-patterns of change, all presented models are thus of an explanatory rather than a predictive nature.

\section{Material and Methods}

\section{Study Area}

The study was conducted in Switzerland $\left(41,293 \mathrm{~km}^{2}\right)$, which topographically can be divided into five major landscape types (Fig. 1). The Plateau is a west-east-oriented lowland corridor (360-600 $\mathrm{m}$ a.s.1.) that is enclosed by mountainous areas: in the north by the Jura Mountains (1000-1600 m a.s.l.) and in the south by the Alps (3000 $4600 \mathrm{~m}$ a.s.l.). The Alps divide the northern part of the country that is dominated by maritime climatic conditions from the southern part, where insubrian conditions prevail. Wet air masses are carried to the Alps from either the North Atlantic or the Mediterranean area, resulting in high annual rainfall at both versants (Northern and Southern Alps). Situated in the rain shadow, west-east-oriented inneralpine valleys of the Central Alps show low precipitation values.

\section{Land-Use/Land-Cover Data}

Data on land use/land cover were obtained from national agricultural statistics and censuses between the 1950s and the 1990s. Because recordings were carried out in intervals

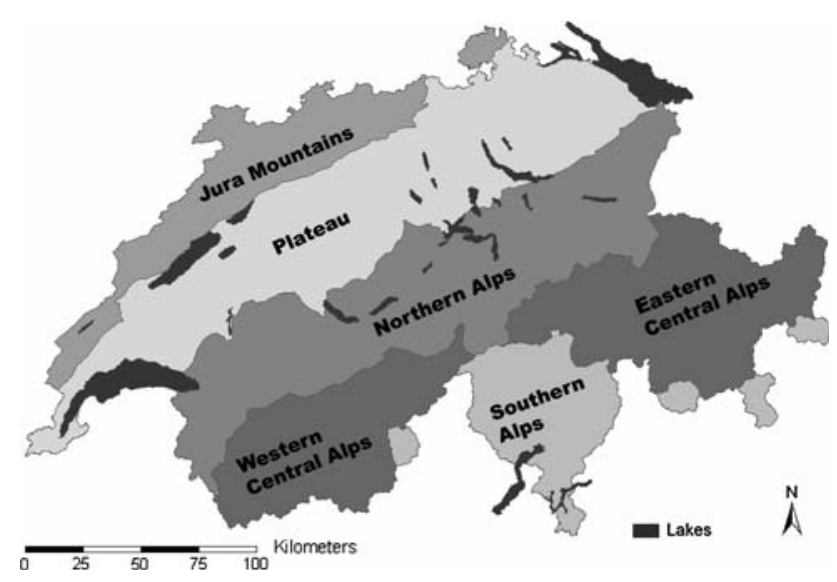

Fig. 1 Spatial division of Switzerland into its five landscape types 
of about 10 years, datasets for five time periods resulted (1950s, 1960s, 1970s, 1980s, and 1990s). The census data were recorded for all 2836 Swiss communes. The latter represent the smallest political entities in Switzerland and the smallest spatial entities in our modeling study. We selected variables that were recorded as consistently as possible over time and that either represented land-use/landcover types directly (e.g., arable land or residential buildings) or could be used as indirect or surrogate indicator (Lindenmayer and others 2002) for farming practices (e.g., farms $>10$ ha or livestock) (Table 1). From the original data, percentages or fractions were calculated to compensate for different large sizes of communes or agricultural areas within them. Transformation rates between two subsequent decades were calculated for all variables by subtracting the later from the earlier state value and dividing the difference by the time lag [e.g., (1960 value - 1950 value)/10 years]. Transformation rates for four transitions were obtained: 1950s-1960s, 1960s-1970s, 1970s-1980s, and 1980s1990s. Negative rates indicated a decrease and positive rates an increase in the respective variable.

\section{Species Data}

Butterfly species data were provided by the Swiss Centre for Faunal Cartography (CSCF). The data originated from natural history collections (NHCs; Graham and others 2004) and comprised records taken between 1951 and 2000. NHC data might have several limitations for spatial modeling (Graham and others 2004) including the following: (1) errors in taxonomic identification and spatial errors; (2) biases due to preferential sampling; and (3) missing species true sample absences. However, the data used here were checked for taxonomic uncertainties by professional entomologists at the CSCF. Furthermore, spatial uncertainties of the records could be reduced by aggregating the records on the communal level, the same level as the landuse/land-cover data. Hence, the communal level was chosen as the appropriate research scale, as it integrated both species and environmental data. Furthermore, the communes represent important management units in Switzerland, because enacted regulations such as for conservation purposes are implemented by the communal authorities.

Because of unsystematic sampling, we assume that not all communes with species presences were sampled in the past. However, we feel that for relating species presenceabsence pattern to site characteristics, this shortcoming is not seriously hampering. We had access to spatiotemporal presence-only data of 200 butterfly species occurring in Switzerland. Out of these, two groups of butterfly species were established with widely differing habitat requirements. Four species occurring in dry grasslands (Walter and others 2003) and inhabiting approximately the same altitudinal range (Gonseth 1987) were summarized as dry grassland species: Melitaea didyma (Spotted Fritillary), Lycaeides idas (Idas Blue), Melitaea cinxia (Glanville Fritillary), and Pseudophilotes baton (Baton Blue) (taxonomy according to Ebert and Rennwald 1993). Another four species appearing predominantly in wetland habitats such as fenlands and bogs (Lepidopterologen-Arbeitsgruppe 2001) were grouped as wetland species: Maculinea teleius (Scarce Large Blue), Maculinea alcon (Alcon Large Blue), Maculinea nausithous (Dusky Large Blue), and Coenonympha tullia (Great Heath). We refer to these selected species as "target species." The grouping of species was necessary brcause single species data would have been too scarce, increasing the probability of errorprone and instable models (Guisan and Thuiller 2005). We did not include woodland species and species with a wide range of suitable habitats, although they might have profited from agricultural abandonment in mountain areas. However, their environmental envelopes encompass so many different habitat types that we would expect no clear responses with the proposed set of methods.

Because the data were presence-only we had to define valid absences for the statistical analyses. The method for calculating absences is described in the Statistical Analyses section.
Table 1 Land-use/land-cover data recorded for the five decades (1950s to the 1990s)

Note: The data were either related to the communal area (CA) or the agricultural area (AA)

\begin{tabular}{lllll}
\hline Acronym & Description & Unit & Ref. & Census years \\
\hline FS2 & Farm size 1-5 ha & Number/ha & AA & $1955,1965,1975,1985,1996$ \\
FS3 & Farm size 5-10 ha & Number/ha & AA & $1955,1965,1975,1985,1996$ \\
FS4 & Farm size $>10$ ha & Number/ha & AA & $1955,1965,1975,1985,1996$ \\
AA & Agricultural area (without forests) & ha/ha & CA & $1955,1965,1975,1985,1996$ \\
AL & Arable land & ha/ha & CA & $1955,1965,1975,1985,1996$ \\
GL & Intensively cultivated grasslands & ha/ha & CA & $1955,1965,1975,1985,1996$ \\
OR & Orchards & ha/ha & CA & $1960,1965,1975,1985,1996$ \\
WL & Wetlands & ha/ha & CA & $1960,1965,1975,1985,1996$ \\
LS & Livestock & Number/ha & AA & $1956,1966,1978,1990,2000$ \\
RB & Residential buildings & Number/ha & CA & $1960,1970,1980,1990,2000$ \\
\hline
\end{tabular}


Statistical Analyses

\section{Cluster Analysis}

Cluster analysis was used as an explorative method to characterize land-use/land-cover change and its corresponding rates of change of all communes investigated (Bätzing 2003; Burel and Baudry 1990). To do so, we clustered the communes based on their rates of change to reveal communes with similar trajectories of change. Thus, a commune always remained in the same cluster, but the cluster means could change from one decade to the next one. To normalize the explanatory variables, these were logarithmically (for frequencies) or arcsin (for percentages) transformed (Mosteller and Tukey 1977) prior to clustering. The analyses were conducted within the $\mathrm{R}$ statistical software package (R 1.9.1-A Language and Environment, C 2004) using the function clara (Kaufman and Rousseeuw 1990), written specifically to handle large datasets. The partitioning was carried out using the Euclidean distance on standardized data. The final number of clusters was defined by calculating the average silhouette width (Kaufman and Rousseeuw 1990; Rousseeuw 1987) for calculations with $2-15$ resulting clusters. Kaufman and Rousseeuw (1990) proposed the following interpretation of the maximal average silhouette width for the entire dataset: $\leq 0.25$ : no substantial structure was found; $0.26-0.5$ : a weak structure was found; $0.51-0.7$ a reasonable structure was found; and 0.71-1: a strong structure was found. Cluster means were derived by averaging the nontransformed data for each cluster that allowed a direct

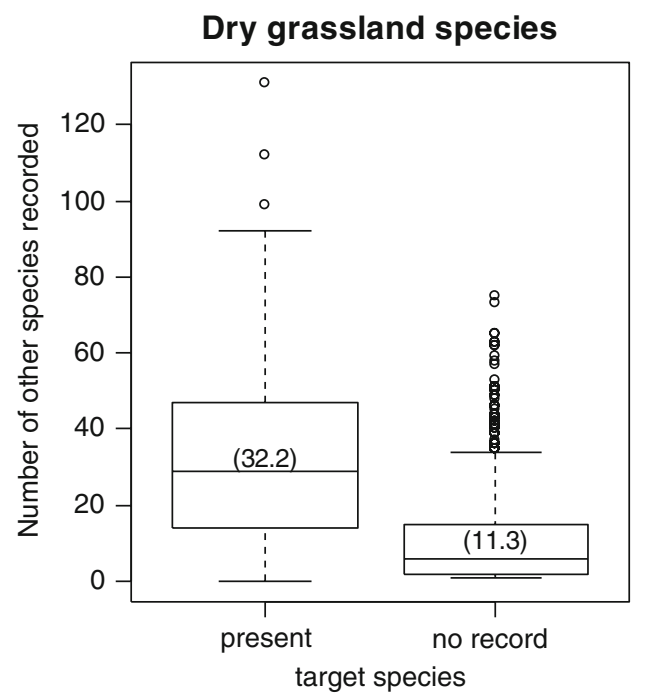

Fig. 2 The boxplots show the number of other butterfly species that were recorded in the same communes and the decades the target species were either present or not recorded. Only communes with at least one target species record were considered. For both groups of target species, the results show that in communes where target species interpretation of the changes in the variables. The results were spatially displayed using ArcGIS (ESRI Inc., Redlands, CA, USA).

\section{Generalized Linear Models (GLMs)}

Species Presence and Absence Datasets We selected communes where the target species were either recorded in two subsequent decades ("presence-presence" events) or only in the earlier but not in the later decade ("presence-no record" events). This setting follows the hypothesis that land-use/land-cover changes occurring in the "presencepresence" event did not lead to species disappearance, whereas the land-use/land-cover changes might have been detrimental for species' survival in the "presence-no record" event.

Because the species data only contained valid presences, the status "no record" of a species could have several reasons: (1) the species remained undetected when the commune was revisited (MacKenzie and others 2003); (2) the species was temporarily absent (e.g., source-sink dynamics; see Pulliam 2000); (3) the commune has not been revisited at all during the subsequent decade; or (4) the species was in fact extinct due to land-use/land-cover changes and was thus absent from the place. In order to define most probable absences, we used presence data of the remaining "nontarget" butterfly species (196 species). We observed that significantly more nontarget butterfly species were reported for the same site and decade when the target species were present themselves (Wilcoxon rank sum test, $P<0.001$ ) (Fig. 2). We therefore selected those

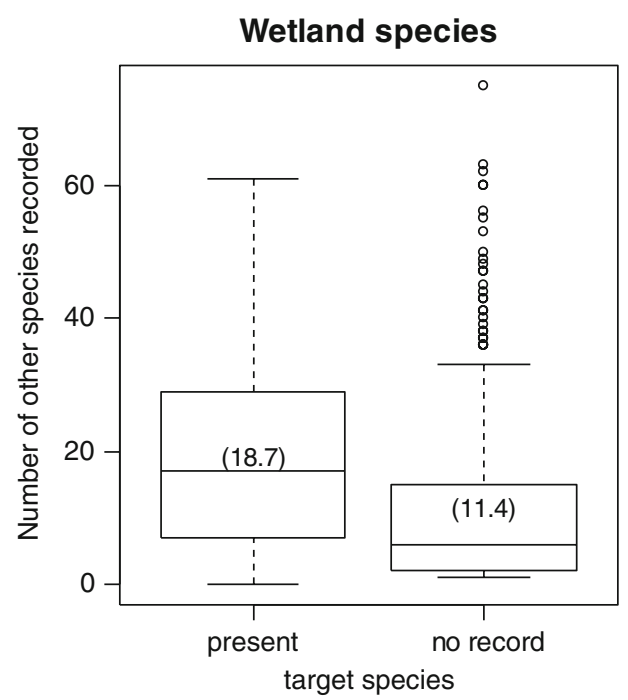

were not recorded also fewer of the other species were found. Means used as threshold values for the further selection of valid absence communes are indicated in brackets. Differences in the means are significant for both species groups (Wilcoxon rank sum test, $P<$ $0.001)$ 
communes as representative absences where more than the average number of nontarget species was recorded. Using this selection method, we reduced the chance of having missed the species when the commune was revisited (case 1) and excluded all cases of false absence that are caused by not revisiting the commune at all (case 3). Missing species records between two presences (case 2) were not considered as valid absences. A commune could have up to four "presence-presence" events, whereas only one "presence-absence" event was possible. One hundred sixty-two and 81 "presence-presence" (persistence) and 89 and 37 "presence-absence" (local disappearance) events were obtained for the dry grassland and the wetland species group, respectively.

Based on these selections we compiled the species datasets that contained (i) the dependent binary variable (species "presence-absence" [1] and "presence-presence" [0] events between the five time periods), (ii) the transformation rates, (iii) the states of the land-use/land-cover variables of each subsequent decade (representing the quantity of land use/ land cover after a period of change), and (iv) the longitude and latitude of the commune centroids. The latter was included to account for possible spatial trends in the data, as our species data were not surveyed using a systematic grid sampling approach and might therefore show differences across the study area. We did not include altitude as explanatory variable, as there was no sufficient information in the historical data to define the altitude where a species was found. Additionally, communes can show large altitudinal gradients. Consequently, calculating average heights would certainly lead to an undesirable bias.

Model Fitting We fitted GLMs with a binomial family and a logistic link function within the R statistical software package to assess relevant drivers for species survival and disappearance, respectively.

The selection of the explanatory variables was conducted using a stepwise backward procedure combined with a bootstrap algorithm that accounted for the temporal correlation in the data. The algorithm started by drawing a bootstrap sample of communes from the species dataset. From this dataset, a GLM was fitted. This procedure was repeated 1000 times to provide a sufficiently large basis to calculate confidence intervals (Davison and Hinkley 1997). To define the $P$-values of the model parameters, we applied the basic bootstrap method (Davison and Hinkley 1997) that estimates the end points of bootstrap $\alpha$-level confidence intervals. Thus, for every explanatory variable, confidence intervals for decreasing significance levels $\alpha$ (from $100 \%$ to $10 \%$ with a decrement of $5 \%$ and from $9 \%$ to $1 \%$ with a decrement of $1 \%$ ) were calculated. Once the variable with the highest $P$-value was defined, it was excluded as explanatory variable. Thereafter, the algorithm restarted by drawing new bootstrap samples. This stepwise procedure was sequentially repeated until only parameters with $P$-values $\leq 0.05$ were retained.

Model Evaluation Each model was evaluated with commonly used indicators [e.g., the percentage of deviance $\left(D^{2}\right)$ explained by the respective GLM, or the adjusted $D^{2}$ (see Guisan and Zimmermann 2000)] that take into account the number of observations and parameters used to build the model. Furthermore, we evaluated the models by using a leave-one-out jack-knife procedure (Guisan and Zimmermann 2000; Manly 1997). This procedure was chosen because the number of occurrences was considered too limited to conduct a proper cross-validation (e.g., 10-fold cross-validation). A new GLM was fitted on a dataset reduced by a single observation at a time. This procedure was repeated until every observation in the dataset was left out once. In each run, the fitted model was used to predict the response for the excluded observation. The predictions were reclassified to presence-absence (1/0) for all threshold values between 0.05 and 0.95 by an increment of 0.05 and compared to the observed presence-absence events by calculating the kappa statistic (Fielding and Bell 1997). The maximum kappa value (max kappa) was then assigned to the model (Engler and others 2004; Guisan and Hofer 2003). Because this evaluation measure is sensitive to the prevalence (i.e., the proportion of presences; see Fielding and Bell 1997; Manel and others 2001), we additionally calculated the threshold independent receiver operating characteristic (ROC) statistic (Fielding and Bell 1997), yielding the area under the curve (AUC) value as a measure of prediction success. The AUC takes values between 0.5 and 1.0, where a value of 0.5 indicates a chance performance and a value of 1.0 represents a model that perfectly separates presences and absences.

The relative importance of each explanatory variable on the model fit was assessed using hierarchical partitioning (Chevan and Sutherland 1991; Mac Nally 2002), available within the $\mathrm{R}$ package hier.part (Walsh and others 2004). This method assesses the degree to which each explanatory variable of a multiple regression model independently and jointly influences the response variable. This finally allows allocating the total degree of explained variance to each variable, enabling us to partition the individual influences of rates and states in our analysis.

\section{Results}

Trajectories and Rates Of Change (Cluster Analysis)

The cluster analysis enabled us to group communes with similar patterns of change in the explanatory variables over 
the five decades. Seven types resulted from the clustering that reached a maximal average silhouette width of 0.22 . The result of the cluster analysis is shown in Fig. 3, which depicts the averaged trajectories of six important variables.

In types 1, 3 and 7 livestock and farm size 4 show high positive rates of change between 1950 and 1970 . This is the result of small farms being merged with bigger farms due to agricultural market forces. It also indicates the strong agricultural intensification that prevailed until the 1970s. Afterwards, the rates of change became negative. The number of livestock decreased as a consequence of the quota limitation for milk production introduced by the Swiss Federal Government in 1977. However, farm size continued to grow while the agricultural area remained on the same level. Geographically, type 1 best matches with communes where dairy farming and the cultivation of wetlands was very prominent. This is the case in the transition zone between the Plateau and the Northern Alps (Fig. 1). Type 3 has strong accordance with intensively cultivated areas and is predominantly found on the Plateau, whereas type 7 is mainly found in mountain areas with low-intensity faming and large farm sizes (Northern Alps and Eastern Central Alps). Type 4 shows high positive rates in the percentage of orchards and is therefore concentrated in regions where fruit-growing has been forced, mainly in the vicinity of lakes in the southwest and northeast of the Plateau. Type 5 is characterized by decreasing densities of all three farm size classes over the five decades. This type is located in regions where changes from a non-intensive to an intensive agriculture have taken place. Geographically it is bound to the Jura Mountains. Type 6 is characterized by a rapid and constant decline in the smallest farm size class and an increase in the largest farm size class. Communes belonging to this type are predominantly found in regions with nonintensive agriculture where small farms are merged with bigger farms to be economically viable. This type is predominantly found in the Western Central Alps and the Southern Alps. Type 2 shows a pronounced increase in residential areas and negative rates for agricultural area. Communes of this type are predominantly located around the larger cities on the Plateau. However, they occur wherever residential areas are built.

\section{Effects of Land-Use/Land Cover Change on Butterfly} Species (GLMs)

\section{Dry Grassland Species Group}

In this model three significant variables $(P \leq 0.05)$ were retained (Table 2, part A). Livestock (LS) is the only state variable and shows a positive coefficient. The remaining variables are rate variables [i.e., rates of change of the density of farm sizes of 5-10 ha (FS3-R) and >10 ha (FS4$\mathrm{R})$ ]. Both variables have negative coefficients. The results indicate that dry grassland species declines were favored in communes showing higher densities of livestock and negative rates in the density of farms of size $>5$ ha. The variables explained $9.7 \%$ of the deviance on average; the
Fig. 3 Trajectories of change (averages) of six variables between the 1950s and 1990s for the seven cluster types obtained in the cluster analysis. Characterization of the types: Type $1=$ increase of livestock and large farms up to 1970 then decrease, areas with prominent dairy farming; Type

$2=$ urbanized and residential areas; Type $3=$ increase of livestock and large farms up to 1970 then decrease, areas with intensive agriculture; Type $4=$ strong expansion of fruitgrowing farms; type $5=$ increasing intensive agriculture; Type $6=$ small farms merge with larger farms; Type $7=$ strong decrease in farms with 5-10 ha in areas with nonintensive agriculture
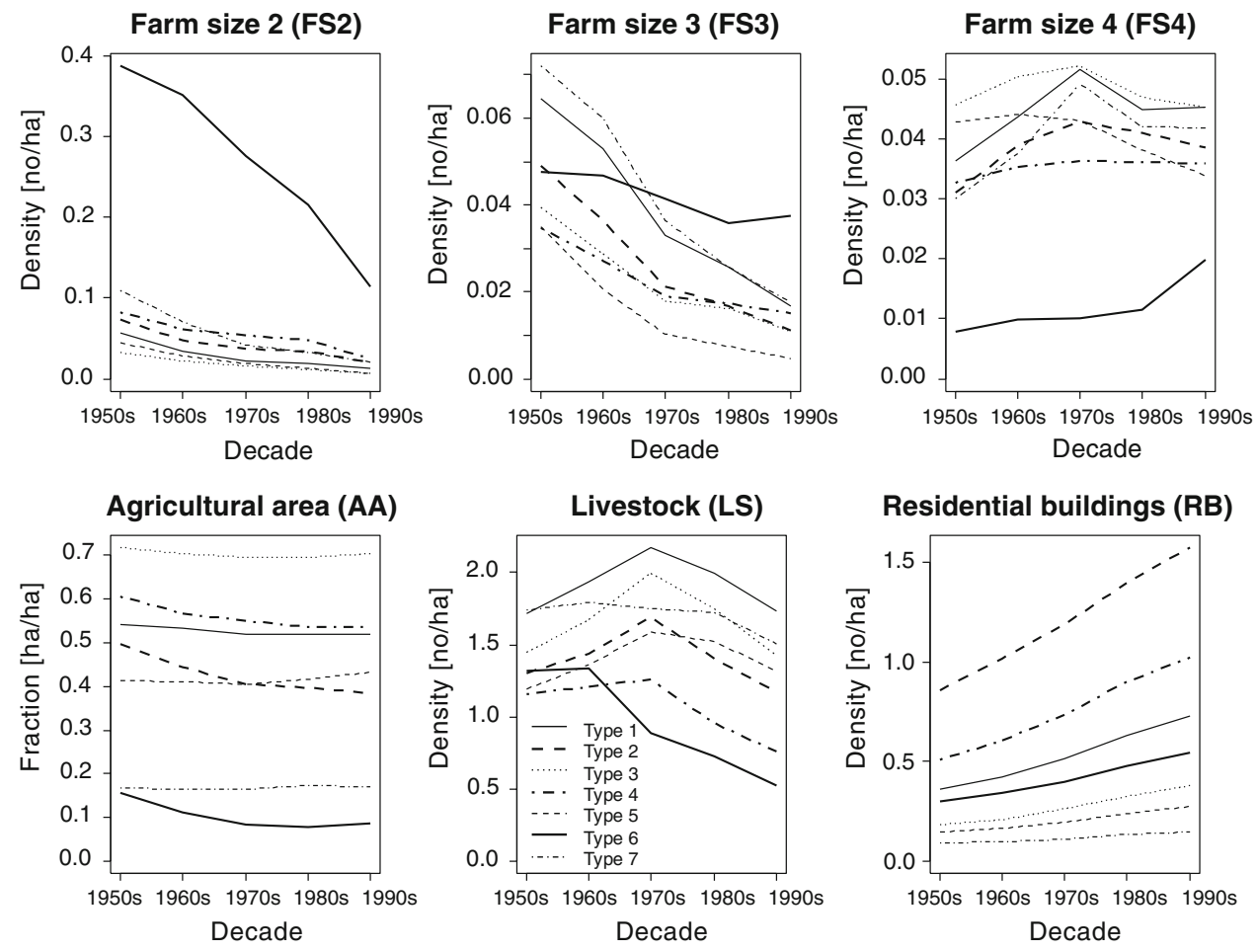
Table 2 Significant drivers of butterfly species disappearance between 1951 and 2000

\begin{tabular}{|c|c|c|c|c|}
\hline Variable & Estimate & Standard error & $P$-Value & $\%$ Total explained deviance \\
\hline \multicolumn{5}{|c|}{ (A) Dry grassland species } \\
\hline LS & 0.96 & 0.27 & $\leq 0.01$ & $39.2( \pm 16.7)$ \\
\hline FS3-R & -3.56 & 0.95 & $\leq 0.01$ & $46.4( \pm 17.7)$ \\
\hline FS4-R & -33.43 & 14.19 & $\leq 0.05$ & $14.4( \pm 10.5)$ \\
\hline \multicolumn{5}{|c|}{ Model fits: $D^{2}=0.09 \pm 0.03$, adjusted $D^{2}=0.08 \pm 0.03$} \\
\hline \multirow{2}{*}{\multicolumn{5}{|c|}{$\begin{array}{l}\text { Model evaluation: } \max \text { kappa }=0.28 \pm 0.07, \text { AUC }=0.69 \pm 0.03 \\
\text { (B) Wetland species }\end{array}$}} \\
\hline & & & & \\
\hline FS4 & -68.19 & 25.10 & $\leq 0.05$ & $44.8( \pm 21.1)$ \\
\hline AA & -3.92 & 1.47 & $\leq 0.05$ & $55.2( \pm 21.1)$ \\
\hline \multicolumn{5}{|c|}{ Model fits: $D^{2}=0.15 \pm 0.06$, adjusted $D^{2}=0.14 \pm 0.06$} \\
\hline \multicolumn{5}{|c|}{ Model evaluation: $\max$ kappa $=0.33 \pm 0.09, \mathrm{AUC}=0.74 \pm 0.05$} \\
\hline
\end{tabular}

variables expressing rates of change explained $5.9 \%$, and livestock as a variable of state explained $3.8 \%$. The low model fit is visible in the low averaged max kappa of 0.28 and an AUC of 0.69. Table 3 (part A) illustrates the stepwise elimination of 19 out of 22 explanatory variables. The elimination sequence does not show any preference for either state or rate variables.

As shown in Fig. 4a, dry grassland species' presencepresence events were more common in communes characterized by a replacement of smaller farm sizes by larger ones (trajectory type 6). Species persistence in this trajectory type was favored by the positive rate of farm size 4 as well as the low density of livestock, as illustrated in Fig. 3. The high proportion of species presence-absence events might be related to the negative rate of farms with a size between 5 and 10 ha (farm size 3 in Fig. 3). In contrast, proportionally more presence-absence than presence-presence events were counted in trajectory type 7 . Here we observed higher densities of livestock compared to type 6, as well as higher negative rates in the farm size class 3 . Both types favored species declines according to the model coefficients. However, positive rates of FS4 and slight decreases in the density of livestock in the most recent decade might have favored species persistence. In trajectory types 4 and 5, the presencepresence and presence-absence events are more or less balanced. Only slight decreases in farm size 3 and average values for farm size 4 and livestock could be the reason for this indifferent behavior.

\section{Wetland Species Group}

Only two significantly correlated variables $(P \leq 0.05)$ expressing land-use/land-cover states were retained in the final model: the agricultural area (AA) and the largest farm size (FS4) (Table 2, part B). Both coefficients were negatively correlated, indicating that species declines were favored in communes with smaller fractions of agricultural area and lower densities of farms with a size $>10$ ha. The averaged $D^{2}$ was $15.3 \%$. The results from the hierarchical partitioning showed that the variable of the largest farm size class explained $6.85 \%$ and the agricultural area explained $8.45 \%$. Model evaluation revealed an averaged max kappa of 0.33 and an AUC of 0.74. Similar to the dry grassland species group (Table 3, part A), the elimination sequence of explanatory variables for wetland species (Table 3, part B) does not show any preference for either state or rate variables during the selection process.

As shown in Fig. 4b, wetland species' presence-presence events occurred proportionally more often than presence-absence events in communes assigned the trajectory types 1 and 3 . According to the model coefficients (Table 2, part B) the generally large agricultural area and the high density of large farms in these communes supports wetland species persistence. Communes of type 6 and 7, on the other hand, have a low and decreasing agricultural area and a low density of large farms, thus favoring presenceabsence events.

\section{Discussion}

\section{Species Reactions to Land-Use/Land-Cover Change} and Rates of Change

The aim of the study was to explore correlations between historical land-use/land-cover changes and observed butterfly species persistence and occurrence. Therefore, not only states of land use/land cover but also the 
corresponding rates of change were considered as explanatory variables. This follows the repeatedly formulated hypothesis that rates of habitat change have a significant

Table 3 Stepwise elimination of explanatory state and rate variables from the initial pool of 22 variables

\begin{tabular}{lllll}
\hline \multicolumn{2}{l}{ Step } & \multicolumn{2}{l}{ (A) Dry grassland butterfly } & \multicolumn{2}{l}{ (B) Wetland butterfly } \\
species & & species & \\
\hline 1 & & OR-R & & FS4-R \\
2 & & LS-R & FS3 & OR-R \\
3 & & FS2-R & & \\
4 & OR & & YCOORD & FS2-R \\
5 & & AL-R & & \\
6 & FS4 & & XCOORD & \\
7 & & RB-R & WL & \\
8 & FS3 & & FS2 & \\
9 & FS2 & & OR & \\
10 & XCOORD & & & FS3-R \\
11 & & WL-R & GL & \\
12 & RB & & AL & \\
13 & YCOORD & & & GL-R \\
14 & AA & & & AL-R \\
15 & AL & & & AA-R \\
16 & & AA-R & & RB-R \\
17 & & GL-R & RB & \\
18 & WL & & & WL-R \\
19 & GL & & LS & \\
20 & & & & LS-R \\
\hline
\end{tabular}

Note: The elimination sequence of the variables from the initial GLM starts with 1 (first elimination) and ends with 19 and 20 respectively (last elimination). (A) is the elimination sequence of dry grassland butterfly species where three explanatory variables were kept in the model. (B) is the elimination sequence of wetland butterfly species where two explanatory variables were kept in the model. Variables expressing rates are indicated by the suffix -R. See Table 1 for an explanation of the variables, except for XCOORD and YCOORD, which represent longitude and latitude of the centroids of the communes influence on species extinction or persistence (Bergman and Kindvall 2004; Brachet and others 1999; Schrott and others 2005). Fahrig (1992) and Keymer and others (2000) claimed that altering rates of habitat change would have a stronger influence species living in ephemeral landscapes, whereas effects of changing habitat area would have a stronger influence on species occupying virtually permanent environments. The butterfly species investigated in this study occupy habitats that rely on a long traditional management and history (Ellenberg 1996). According to these authors, butterfly species persistence would therefore be more endangered by changes in the amount of remaining habitat. Our empirical data for the dry grassland butterfly species confirmed this hypothesis and showed that both states and rates of change are important drivers for species survival. However, the rates have a higher explanatory power, and the negative transformation rates of the density of farms with an agricultural area larger than 5 ha suggest it is a major driver of species decline. At first glance, this result is surprising, for we would expect more favorable conditions for dry grassland species as the number of large farms with an intensive production decreases. Although this is certainly true for the favorable area of large farms where intensified production increases the productivity (Bätzing 2003), it does not apply to the marginal area of large farms. These marginalized areas became increasingly available as more small farms merged into larger farm complexes over the last 50 years. These mergers caused farmers to concentrate on favorable areas and many unfavorable, marginal agricultural areas that traditionally require much manual work have become abandoned or extensively used pastures. On these extensively managed pastures, butterfly species diversity is similar to the one of extensively used meadows (Hohl 2006), and the species analyzed in this study occur frequently in such habitats (Lepidopterologen-Arbeitsgruppe 2001). Unless these marginal areas are regularly cleared,
Fig. 4 Occurrence of species presence-presence and presence-absence events in the seven trajectory types for dry grassland species (a) and wetland species (b). Characterization of the types according to Fig. 3
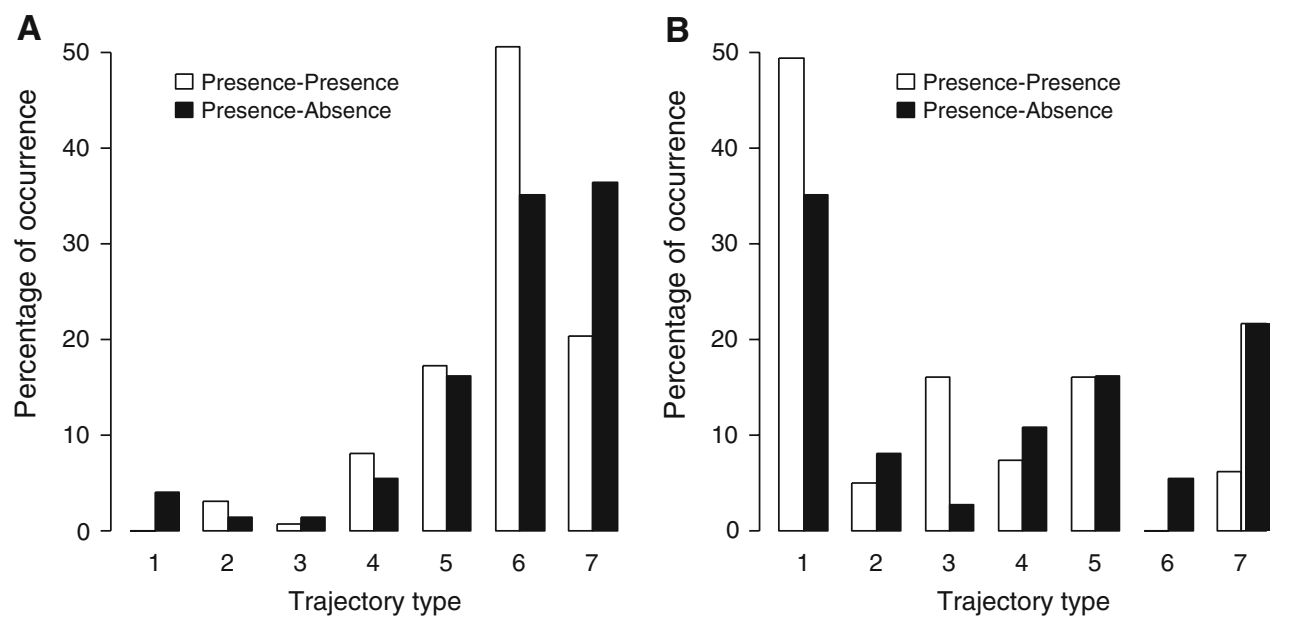
the ongoing abandonment will eventually result in dense shrub vegetation and forest, hence decreasing dry grassland species persistence (Erhardt 1985; Hohl 2006; Lepidopterologen-Arbeitsgruppe 2001). Consequently, we echo concerns of nature management agencies that the favorable butterfly habitat conditions might not last for a long time. Indeed, quantitative analyses showed that between the 1980s and 1990s, spontaneous reforestation has mainly occurred on unfavorable, marginal areas (Baur and others 2006). These sites often harbor species-rich dry grasslands that will be reduced in size with continuing forest expansion (Baur and others 2006; Eggenberg and others 2001). Bergman and Kindvall (2004) came to similar conclusions by analyzing the extinction risk of the butterfly species Lopinga achine in relation to the rate of canopy closure of the species' habitat. This butterfly lives in partly open oak woodland where the traditional management of grazing or mowing prevents the canopy to close. The model of Bergman and Kindvall (2004) shows that the survival of the populations in the next 100 years will be seriously affected by the rate of canopy closure. The latter affects the presence or absence of the species' host plant. The study of Bergman and Kindvall (2004) confirms our concern that the positive impacts of the small-to-large farm transformation on dry grassland species persistence might not be sustained in the long run unless regular clearings take place.

The other significantly influencing explanatory variable for dry grassland species disappearance is the density of livestock in the communes. This state variable was introduced as a surrogate variable to capture habitat quality characteristics like the amount of fertilizer spread in the commune or the intensity of grazing, given that no historical records were available to estimate rates. The correlation showed that increasing numbers of livestock had a negative effect on the survival of the dry grassland butterfly species. We conclude that with the increase in livestock, more dry grasslands were turned into nutrientrich meadows or pastures that caused habitat loss for the specialized butterfly species (Baur and others 2006; Erhardt 1985; Hohl 2006).

In the case of the wetland butterfly species group, larger farm sizes and larger agricultural areas have promoted species survival. As with the dry grassland species, we assume that the larger the farm size, the lower the economic pressure to use all available agricultural land intensively, leaving wetlands as nonintensively cultivated areas. Surprisingly, neither wetlands nor the rates of wetland change were retained as explanatory variables in the model. This might have resulted from the fact that wetlands showed a steep decline until the 1980s, followed by a strong increase until the 1990s, so that these divergent trends were mutually compensated and no discrimination was achieved. The sudden increase in cultivated wetlands in the agricultural statistics can be explained with the refunds paid since the 1990s for the maintenance of ecological compensation areas (BFS 1996).

For nature conservation purposes, it would be desirable to quantify tolerable maximum rates of change to design effective preservation programs. Our model results showed that declines of dry grassland butterfly species were more prominent in communes where such changes happened more rapidly over the last 50 years. However, despite the fact that we were able to show statistically significant relationships between the rate of change and species decline, the models do not allow deriving maximum tolerable rates of change. To achieve such results one would have to analyze local population density data with (meta)population models using dynamic environments. At the moment, such datasets are not available at the national level and for many historical time steps.

\section{Limitations of the Historical Analysis}

Statistical census data are a valuable and efficient alternative to maps, aerial photographs, or remote sensing data for describing land-use/land-cover changes over broad extents. Data on agricultural structures (e.g., farm sizes, number of livestock) that cannot be obtained form cartographic representations, make censuses an interesting data source. Nevertheless, some limitations have to be considered. (1) The spatial resolution of such analyses is constrained by the extents of the communes and no further spatial differentiation is possible within these minimum units to find out where exactly certain land uses/land covers have occurred. However, the aggregated level achieved with census data is not a disadvantage given that historical species observations are often missing exact spatial references, and thus species occurrence is better represented on a communal level. (2) Census data often display cultivated land categories only. This restriction can be a real drawback for ecological analyses, especially when unproductive areas (mostly seminatural vegetation as found, e.g., on floodplains or bogs) are not represented in such datasets.

Our aim to explain species occurrence with a simple, statistically significant set of prominent state and rate variables yielded rather low model fits, leaving much deviance unexplained. We attribute these findings to (1) the statistically rigid variable selection, (2) the selection of valid historical species presences/absences, and (3) the lack of available historical variables that have a more direct impact on species occurrence [more proximal according to Austin (1980)]. The latter point is a repeatedly mentioned problem with historical datasets. Ideally, access to historical information on microhabitat and vegetation composition, data on meadow cutting, or information on intensive pasturing or eutrophication would have improved 
our models. They are all considered important factors related to butterfly species occurrence (LepidopterologenArbeitsgruppe 2001), and their inclusion in our statistical analysis might have substantially increased model performance. However, these factors often show strong annual variations (even single events might have strong impacts) and, thus, are hard to reconstruct in historical times. Our attempt to approximate such impacts with valuable surrogate data such as the density of livestock as surrogate for the intensity of pasturing and fertilization was quite successful. Furthermore, we are aware that factors such as climate or the genetic impoverishment occurring in small populations might contribute to more explanatory power of the models.

\section{Management Implications}

We have evidence that dry grassland butterfly species have decreased over the 50 years of investigation due to intensifications of formerly extensively used pastures, transformations of unfertilized hay meadows into fertilized meadows, and transformation of marginal grassland sites to forests. In order to support species persistence, we suggest maintaining or mimicking the traditional management on unfertilized dry grasslands. This is not contradictory to modern farm management on large farms. Moreover, we found a positive effect of large farm occurrence on dry grassland species persistence. However, the effect is only long-lasting if the marginal areas created in the course of farm mergers are regularly cleared of regenerating shrubs and trees or are occasionally grazed by animals like goats or sheep. Preservation of wetland butterfly species is most effective when small wetland areas are traditionally managed. Unlike goat or sheep grazing, management of small wetlands is an economic burden for most farms and should be financially compensated. In Switzerland, most farms participate in agri-environmental programs and are compensated for their efforts (and financial losses) on small ecological compensation areas.

\section{Conclusions}

This article shows that historical land-use/land-cover changes could be linked to decreases in butterfly species from wetland and dry grassland habitats. The main conclusions of the article are as follows:

1. Historical data should be carefully checked prior to building a model. The (historical) information was frequently collected or assembled for purposes other than spatial modeling and often lacks a sound sampling strategy.
2. Cluster and trajectory analyses as described in this article are welcome complements to traditional regression analysis (GLM, GAM). They enable us to interpret the results of the regressions within the context of all explanatory variables and yield a detailed spatial context that goes far beyond a simple thematic map.

3. State and rate variables are important drivers of our species persistence/disappearance. For dry grassland species, the rate variables explain more variance than the state variables. This empirical finding confirms several hypotheses stated in the literature (Fahrig 1992; Keymer and others 2000).

4. We have evidence that small-to-large farm transformation has positive effects on the persistence of the two groups of butterfly species. The positive effect can only be sustained in the long run if large farms adopt innovative management strategies (e.g., clearing or grazing marginal grassland areas regularly).

Acknowledgments This study was supported by a grant from the Swiss National Science Foundation (application No. 4048-064460) in the program "Landscapes and Habitats of the Alps" (NRP 48). We are thankful to the Swiss Federal Statistical Office for providing most recent census data. We thank Christoph Buser from the Seminar for Statistics of the Swiss Federal Institute of Technology Zurich (ETHZ) for constructive discussion on the statistical part and appreciate helpful comments of Janine Bolliger on an earlier draft of this article. We are grateful to two anonymous reviewers who provided constructive comments on the manuscript and to Thomas Edwards for linguistic corrections.

\section{References}

Austin MP (1980) Searching for a model for use in vegetation analysis. Vegetatio 42:11-21

Bätzing W (2003) Die Alpen. Geschichte und Zukunft einer europäischen Kulturlandschaft, 2nd edn. Beck, München

Baur P, Bebi P, Gellrich M, Rutherford G (2006) WaSAlp: Waldausdehnung im Schweizer Alpenraum. Eine quantitative Analyse naturräumlicher und sozio-ökonomischer Ursachen unter besonderer Berücksichtigung des Agrarstrukturwandels. Eidgenössische Forschungsanstalt für Wald, Schnee und Landschaft WSL, Birmensdorf

Benton TG, Bryant DM, Cole L, Crick HQP (2002) Linking agricultural practice to insect and bird populations: a historical study over three decades. Journal of Applied Ecology 39:673-687

Bergman KO, Kindvall O (2004) Population viability analysis of the butterfly Lopinga achine in a changing landscape in Sweden. Ecography 27:49-58

BFS (Bundesamt für Statistik) (1996) Strukturwandel und Innovation in der Landwirtschaft. Landwirtschaftliche Betriebszählung 1996. Bundesamt für Statistik, Bern

Brachet S, Olivieri I, Godelle B, Klein E, Frascaria-Lacoste N, Gouyon PH (1999) Dispersal and metapopulation viability in a heterogeneous landscape. Journal of Theoretical Biology 198: 479-495

Burel F, Baudry J (1990) Structural dynamic of a hedgerow network landscape in Brittany France. Landscape Ecology 4:197-210 
Chamberlain DE, Fuller RJ, Bunce RGH, Duckworth JC, Shrubb M (2000) Changes in the abundance of farmland birds in relation to the timing of agricultural intensification in England and Wales. Journal of Applied Ecology 37:771-788

Chevan A, Sutherland M (1991) Hierarchical partitioning. American Statistician 45:90-96

Cousins SAO, Eriksson O (2002) The influence of management history and habitat on plant species richness in a rural hemiboreal landscape, Sweden. Landscape Ecology 17:517-529

Davison AC, Hinkley DV (1997) Bootstrap methods and their application. Cambridge University Press, Cambridge, $582 \mathrm{pp}$

Dullinger S, Dirnböck T, Greimler J, Grabherr G (2003) A resampling approach for evaluating effects of pasture abandonment on subalpine plant species diversity. Journal of Vegetation Science $14: 243-252$

Ebert G, Rennwald E (1993) Die Schmetterlinge Baden-Württembergs. Ulmer, Stuttgart, $552 \mathrm{pp}$

Eggenberg S, Dalang T, Dipner M, Mayer C (2001) Kartierung und Bewertung der Trockenwiesen und -weiden von nationaler Bedeutung. Technischer Bericht. Bundesamt für Umwelt, Wald und Landschaft (BUWAL), Bern, $251 \mathrm{pp}$

Ellenberg H (1996) Vegetation Mitteleuropas mit den Alpen in ökologischer, dynamischer und historischer Sicht. Ulmer, Stuttgart, $1095 \mathrm{pp}$

Engler R, Guisan A, Rechsteiner L (2004) An improved approach for predicting the distribution of rare and endangered species from occurrence and pseudo-absence data. Journal of Applied Ecology 41:263-274

Erhardt A (1985) Wiesen und Brachland als Lebensraum für Schmetterlinge. Eine Feldstudie im Tavetsch (GR). Birkhäuser Verlag, Basel, $154 \mathrm{pp}$

Ewald KC (1978) Der Landschaftswandel: zur Veränderung schweizerischer Kulturlandschaften im 20. Jahrhundert. Eidgenössische Anstalt für das Forstliche Versuchswesen, Birmensdorf, $253 \mathrm{pp}$

Fahrig L (1992) Relative importance of spatial and temporal scales in a patchy environment. Theoretical Population Biology 41:300314

Fielding AH, Bell JF (1997) A review of methods for the assessment of prediction errors in conservation presence/absence models. Environmental Conservation 24:38-49

Gaston KJ, Blackburn TM, Goldewijk KK (2003) Habitat conversion and global avian biodiversity loss. Proceedings of the Royal Society London Series-B Biological Sciences 270:1293-1300

Gonseth Y (1987) Verbreitungsatlas der Tagfalter der Schweiz (Lepidoptera Rhopalocera). Centre Suisse de Carthographie de la Faune, Neuchâtel, 242 pp

Graham CH, Ferrier S, Huettman F, Moritz C, Peterson AT (2004) New developments in museum-based informatics and applications in biodiversity analysis. Trends in Ecology \& Evolution 19:497-503

Guisan A, Hofer U (2003) Predicting reptile distributions at the mesoscale: relation to climate and topography. Journal of Biogeography 30:1233-1243

Guisan A, Thuiller W (2005) Predicting species distribution: offering more than simple habitat models? Ecology Letters 8:993-1009

Guisan A, Zimmermann NE (2000) Predictive habitat distribution models in ecology. Ecological Modelling 135:147-186

Hohl M (2006) Spatial and temporal variation of grasshopper and butterfly communities in differently managed semi-natural grasslands of the Swiss Alps. Thesis No. 16625, Swiss Federal Institute of Technology Zurich (ETHZ). Zurich, 98 pp
Hutchinson CF, Unruh JD, Bahre CJ (2000) Land use vs. climate as causes of vegetation change: a study in SE Arizona. Global Environmental Change 10:47-55

Kaufman L, Rousseeuw RJ (1990) Finding groups in data: an introduction to cluster analysis. Wiley, New York, $342 \mathrm{pp}$

Keymer JE, Marquet PA, Velasco-Hernandez JX, Levin SA (2000) Extinction thresholds and metapopulation persistence in dynamic landscapes. American Naturalist 156:478-494

Laiolo P, Dondero F, Ciliento E, RolandoA A (2004) Consequences of pastoral abandonment for the structure and diversity of the alpine avifauna. Journal of Applied Ecology 41:294-304

Lepidopterologen-Arbeitsgruppe (2001) Tagfalter und ihre Lebensräume. Arten, Gefährdung, Schutz. Schweizerischer Bund für Naturschutz, Basel, 516 pp

Lindenmayer DB, Cunningham RB, Donnelly CF, Lesslie R (2002) On the use of landscape surrogates as ecological indicators in fragmented forests. Forest Ecology and Management 159: 203-216

Lundström-Gilliéron C, Schlaepfer R (2003) Hare abundance as an indicator for urbanisation and intensification of agriculture in Western Europe. Ecological Modelling 168:283-301

Mac Nally R (2002) Multiple regression and inference in ecology and conservation biology: further comments on identifying important predictor variables. Biodiversity and Conservation 11: 1397-1401

MacKenzie DI, Nichols JD, Hines JE, Knutson MG, Franklin AB (2003) Estimating site occupancy, colonization, and local extinction when a species is detected imperfectly. Ecology 84:2200-2207

Manel S, Williams HC, Ormerod SJ (2001) Evaluating presenceabsence models in ecology: the need to account for prevalence. Journal of Applied Ecology 38:921-931

Manly BFJ (1997) Randomization, bootstrap and Monte Carlo methods in biology. Chapman \& Hall, London, $428 \mathrm{pp}$

Mosteller F, Tukey J (1977) Data analysis and regression. AddisonWesley, New York, $588 \mathrm{pp}$

Pulliam HR (2000) On the relationship between niche and distribution. Ecology Letters 3:349-361

Rousseeuw PJ (1987) Silhouettes: a graphical aid to the interpretation and validation of cluster-analysis. Journal of Computational and Applied Mathematics 20:53-65

Schneeberger N, Bürgi M, Kienast F (2007) Rates of landscape change at the northern fringe of the Swiss Alps: historical and recent tendencies. Landscape and Urban Planning 80:127-136

Schrott GR, With KA, King ATW (2005) On the importance of landscape history for assessing extinction risk. Ecological Applications 15:493-506

Söderström B, Svensson B, Vessby K, Glimskar A (2001) Plants, insects and birds in semi-natural pastures in relation to local habitat and landscape factors. Biodiversity and Conservation 10:1839-1863

Walsh CJ, Papas PJ, Crowther D, Yoo J (2004) Stormwater drainage pipes as a threat to a stream-dwelling amphipod of conservation significance, Austrogammarus australis, in southeastern Australia. Biodiversity and Conservation 13:781-793

Walter T, Schneider K and Gonseth Y (2003) Pages 152-155 in OECD (ed.), Eco-fauna-database: A tool for both determining the faunistic potential and estimating impacts of land use on animal species. OECD, Paris 